Journal of

Nutrigenetics

Nutrigenomics

\author{
Allayee, H. 140 \\ Consoli, L. 129 \\ Fradet, V. 149 \\ Heinrich, J. 119 \\ Hodis, H.N. 140 \\ Illig, T. 119 \\ Koletzko, B. 119
}

Lattka, E. 119

Martinelli, N. 129

Olivieri, O. 129

Reese, A.C. 149

Roth, N. 140

Simopoulos, A.P. 117

Witte, J.S. 149

\title{
Subject Index Vol. 2, No. 3, 2009
}

Arachidonic acid 119

Atopy 119

Cardiovascular disease 140

Coronary artery disease 129

Cyclooxygenase 2149

Desaturase 129

$\Delta^{5}$ desaturase 119

$\Delta^{6}$ desaturase 119

Diet 149

FADS genes 129

Fatty acids 140 $\omega-3$ fatty acids 129,149

$\omega-6$ fatty acids 129

Gene(s) 140, 149

Genetic variation 149

Inflammation 129

Leukotriene 140

5-Lipoxygenase 140

Polyunsaturated fatty acids 149

Prostatic neoplasms 149

Single nucleotide polymorphism 119, 149 